\title{
Evaluation of Patients Satisfaction following Caesarean Section in a Secondary level District Hospital
}

\author{
SANKAR KUMAR BASAK ${ }^{1}$, ZANNATUL FERDOSH ${ }^{2}$, REHENA BEGUM ${ }^{3}$, NASIM IFTEKHAR MAHMUD ${ }^{4}$
}

\begin{abstract}
:
Objective: To assess the level of satisfaction with caesarean delivery and to see the relation between different parameters and satisfaction.

Materials \& Methods: This cross sectional study was done in the department of Obstetrics \& Gynaecology of the District Sadar Hospital, Laxmipur during the period of $1^{\text {st }}$ January to $30^{\text {th }}$ June 2017. A total of 423 post-caesarean women were included in the study. The structured questionnaires were used for the collection of data from the patients and the data were processed and analyzed with the help of software SPSS.

Results: During the study period, among the 465 caesarean delivery 423 were enrolled for the study. The mean age of the patients was $23.99 \pm 5.29$ years and mean parity was $1.22 \pm 1.27$. Initial negative reaction to the decision of caesaren section was expressed by $71.9 \%$ of the patients, $18.4 \%$ remained indifferent and $9.7 \%$ showed positive reaction. The major reasons of initial negative reaction were fear of death and dislike of caesarean section. The satisfaction following caesarean delivery was significantly associated with age, educational status and initial positive and negative reaction to the decision of caesarean section. Three hundred and fifty five (83.9\%) women expressed their overall satisfaction following caesarean section.
\end{abstract}

Conclusion: Most patients expressed their overall satisfaction to caesarean delivery.

Key words: Satisfaction, Caesarean section.

Introduction:

Caesarean section (CS) is the most frequent major abdominal surgery performed worldwide ${ }^{1}$.Increasing rates of CS is a matter of concern is many countries ${ }^{2}$ and in the USA caesarean delivery accounts for $30 \%$ of all births ${ }^{3}$. The increasing caesarean rates not only exists in developed countries, it also reported from developing countries like Tanzania ${ }^{4}$ and Bangladesh $^{5}$. In developed countries, while fear of birth, increasing maternal age at marriage and first pregnancy, fear of pelvic floor damage, and genital prolapse in later years are implicated reasons ${ }^{6-10}$, in developing countries, the view that caesarean section is the surest way to a live birth is believed to be a critical factor underlying their choice ${ }^{11}$. As a result, the numbers of pregnant women who have previously had a caesarean are also rising, however, the rates of Trial of Labour after CS are decreasing world wide ${ }^{12}$.

There are known risks of elective CS such as the increased risk of persistent pulmonary hypertension and respiratory distress syndrome in the new born ${ }^{13,14}$. A higher likelihood of uterine infection, wound complication, cardiopulmonary and thromboembolic condition ${ }^{15}$ and future ectopic pregnancies and placental problems ${ }^{16}$ are also

1. Senior Consultant- Gynae \& Obs, District Sadar Hospital, Laxmipur.

2. Medical Officer, District Sadar Hospital, Laxmipur.

3. Medical Officer, District Sadar Hospital, Laxmipur.

4. Junior Consultant- Anaesthesia, District Sadar Hospital, Laxmipur.

Address for correspondence: Dr. Sankar Kumar Basak, Principal author of the article \& Senior Consultant-Gyne \& Obs District Sadar Hospital, Laxmipur. E-mail: drskbasak16@gmail.com, Mobile: 01712-560251 
observed following CS. However, improved quality of anaesthesia service, good surgical technique, available blood transfusion facility and antibiotic therapy have raised the safety profile of surgical delivery. CS is still being perceived as an abnormal means of delivery by some women in developing countries ${ }^{17}$, the negative view of CS by them has led to gross under-utilization of the procedure compared to the large burden of obstetric morbidity requiring resolution by $\mathrm{CS}^{18}$.

Patient satisfaction considered as one of the most important quality dimensions and key success indicators in health care ${ }^{19}$. Oliver ${ }^{20}$ defines satisfaction as the consumer's fulfillment response, a post consumption judgment by the consumer that a service provides a pleasing level of consumption related fulfillment. Here consumers are the postcaesarean patients.

Though CS is an essential component in emergency obstetric care a few women prefer it as a mode of delivery ${ }^{21}$. It is important to accept it as a beneficial procedure for the pregnant mother when needed. Women's satisfaction with CS is an essential factor for such acceptance. Maternal satisfaction is multidimensional and is influenced both by medical and social factors.

Satisfaction with the mode of delivery is a useful indicator of compliance and re-attendance for treatment, and influences future management and provision of health care. Dissatisfaction can lead to sexual dysfunction, aversion to pregnancy and delivery, and increased complaints and litigation ${ }^{22,23}$.

Every service provider should assess how much he/ she can satisfy his/her clients. Satisfied clients are likely to exhibit favorable behaviour, which are beneficial to the healthcare provider's long-term success. This study was designed as a preliminary study to assess the level of satisfaction among the parturients who had recently delivered by caesarean section and it may provide a reference for future indepth analysis.

\section{Materials and Methods:}

This descriptive type of cross-sectional study was conducted in the department of Obstetrics \& Gynaecology of the District Sadar Hospital, Laxmipur from $1^{\text {st }}$ January to $30^{\text {th }}$ June 2017 . The District Sadar Hospital, Laxmipur is a 100 bedded secondary level hospital. During the study period total of 893 delivery occurred, among them 465 women delivered by CS. The written permission for the study was taken from the proper authority of the hospital.

The post-caesarean patients were the study population. Patients were interviewed on $2^{\text {nd }}$ to $6^{\text {th }}$ post-operative day after the recovery of initial trauma of surgery. The inclusion criteria were met by 443 of 465 post- caesarean women, among them 20 mothers withdrawn themselves from the study and 423 were enrolled in the study. Exclusion criteria were postpartum eclampsia, severe postpartum haemorrhage requiring re-laparotomy with hysterectomy, postpartum psychosis, severe cardiac and respiratory diseases, wound infection with burst abdomen or any condition requiring referral to the higher centre and severe neonatal conditions or neonatal death. These patients were severely ill and were unwilling or unable to take part in the study, therefore they were excluded.

The variables included in the study were age, parity, educational status, types of CS. The initial reaction to the decision of CS, the reasons of reaction and the satisfaction following CS were also studied. The structured questionnaires were prepared which include all the variables of interest. After explaining the objectives of the study and assuring that her response would never affect her treatment, verbal consent for participation in the study was taken.

The data were collected from the patients on variables of interest using the structured interview, observation and from the history sheet of the patients. The collected data were processed with the help of software SPSS (Statistical Package for Social Sciences) version-22 and analyzed. The test statistics used to analyze the data were descriptive statistics, Chi-square $\left(\chi^{2}\right)$ probability test for qualitative variables and unpaired student t-test for quantitative variables. For all analytical tests level of significance were set at $p<0.05$.

\section{Results:}

The socio-demographic characteristics of the patients are presented in the table-I. The mean age of the patients was $23.99 \pm 5.29$ years (range $18-45$ years). Among the study population 240 (56.7\%) were multipara and $183(43.3 \%)$ were primipara. More than $90 \%$ of the patients had secondary and tertiary level of education. Emergency CS occurred in 301 (71.2\%) cases and remaining 122 (28.8\%) were elective CS. 
Table-I

Sociodemographic and clinical parameters of the patients.

\begin{tabular}{lcc}
\hline Parameters & $\begin{array}{c}\text { Number } \\
(\mathrm{n}=423)\end{array}$ & Percentage \\
\hline Age (years) & & \\
$\quad<20$ & 66 & 15.6 \\
$20-29$ & 291 & 68.8 \\
$30-39$ & 61 & 14.4 \\
$>39$ & 5 & 1.2 \\
Parity & & \\
0 & 183 & 43.3 \\
$1-4$ & 237 & 56.0 \\
$\quad 5$ & 3 & 0.7 \\
Educational Status ${ }^{\mathrm{a}}$ & & \\
$\quad$ Primary & 41 & 9.7 \\
$\quad$ Secondary & 185 & 43.7 \\
$\quad$ Tertiary & 197 & 46.6 \\
Types of caesarean section ${ }^{\mathrm{b}}$ & \\
$\quad$ Elective & 122 & 28.8 \\
$\quad$ Emergency & 301 & 71.2 \\
\hline
\end{tabular}

a) Primary indicates 5 years of basic education; secondary indicates 12 years of education; tertiary indicates graduation or Masters or same level.

b) Elective means planned caesarean section without immediate threat to fetus or mother; emergency means patient is in labour or ruptured membrane or having immediate threat to mother or fetus.
Table-Il shows the initial reaction and their reasons to decision of caesarean delivery. Most of the patients $(90.3 \%)$ were negative and indifferent to the decision of caesarean delivery. The major reasons of negative reaction were fear and dislike of CS. The table-III \& IV represent the relation between the study parameters and the level of satisfaction following caesarean section. The statistically significant relation was established between satisfaction with CS and mean age, educational qualification and initial reaction to CS. Among the study population, 355 (83.9\%) patients expressed their satisfaction with CS as a mode of delivery.

Table-II

Reasons of Initial reaction to decision of caesarean section.

\begin{tabular}{lcc}
\hline Initial reaction and reason & Number & Percentage \\
\hline Positive ( $n=41)$ & & \\
$\quad$ Prolonged Labour Pain & 22 & 53.7 \\
$\quad$ Previous experience & 14 & 34.1 \\
$\quad$ No reason & 5 & 12.2 \\
Negative ( $n=304)$ & & \\
Fear & 177 & 58.2 \\
$\quad$ Dislike & 57 & 18.8 \\
No reason & 45 & 14.8 \\
$\quad$ Previous bad experience & 14 & 4.6 \\
$\quad$ Suddenness & 11 & 3.6 \\
Indifferent ( $n=78)$ & & \\
$\quad$ Previous experience & 51 & 65.4 \\
$\quad$ No reason & 27 & 34.6 \\
\hline
\end{tabular}

Table-III

Relation between demographic and clinical parameters and satisfaction following caesarean section.

\begin{tabular}{|c|c|c|c|c|}
\hline \multirow[t]{2}{*}{ Parameters } & \multicolumn{2}{|c|}{$\begin{array}{c}\text { Satisfaction following } \\
\text { caesarean section }\end{array}$} & \multirow[t]{2}{*}{$\begin{array}{l}\chi^{2} \text { value/ } \\
\text { t value }\end{array}$} & \multirow[t]{2}{*}{$p$ value } \\
\hline & $\begin{array}{c}\text { Satisfied } \\
(n=355) \\
\text { No }(\%) \\
\end{array}$ & $\begin{array}{c}\text { Not satisfied } \\
(n=68) \\
\text { No }(\%)\end{array}$ & & \\
\hline \multicolumn{5}{|l|}{ Age (in years) } \\
\hline Mean SD & $24.3 \pm 5.3$ & $22.1 \pm 4.5$ & 3.115 & 0.002 \\
\hline \multicolumn{5}{|l|}{ Parity } \\
\hline 0 & $157(44.2)$ & $26(38.2)$ & 1.52 & 0.467 \\
\hline $1-4$ & $195(54.9)$ & $42(61.8)$ & & \\
\hline$\geq 5$ & $03(0.9)$ & $0(0.0)$ & & \\
\hline \multicolumn{5}{|c|}{ Educational status } \\
\hline Primary & $39(11.0)$ & $2(3.0)$ & 8.07 & 0.018 \\
\hline Secondary & $146(41.1)$ & $39(57.3)$ & & \\
\hline Tertiary & $170(47.9)$ & $27(39.7)$ & & \\
\hline \multicolumn{5}{|c|}{ Types of caesarean section } \\
\hline Elective & 109 (30.7) & $13(19.1)$ & 3.73 & 0.053 \\
\hline Emergency & $246(69.3)$ & $55(80.9)$ & & \\
\hline
\end{tabular}

$\mathrm{P}$ value measured by Unpaired student t-test for quantitative variables and Chi-square test for qualitative variables. 
Table-IV

Relation between initial reaction to decision of caesarean section and satisfaction following caesarean section.

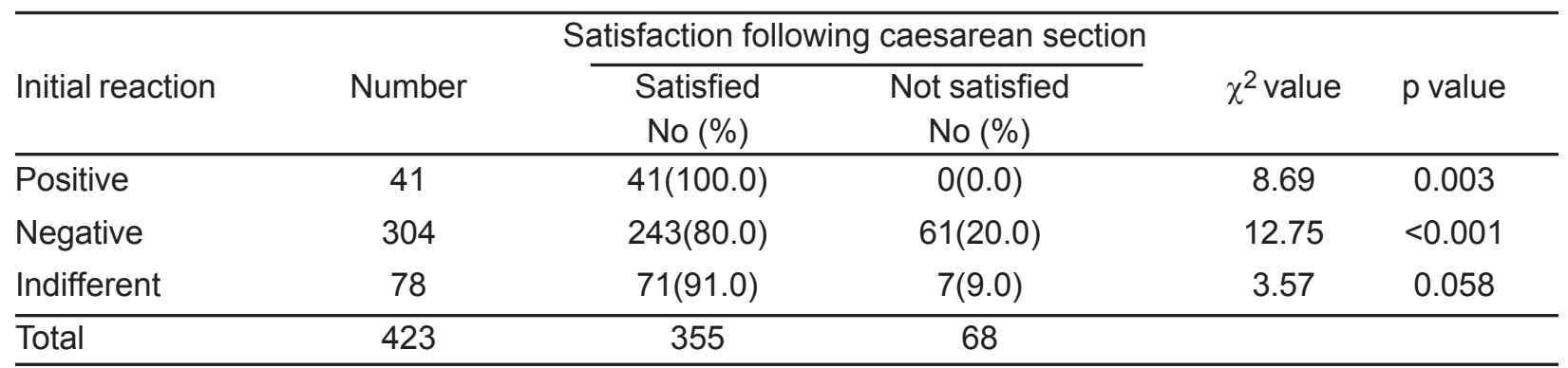

\section{Discussion:}

Satisfaction provides the positive image of health services delivered. Jackson et $\mathrm{al}^{24}$ suggests that patient satisfaction is strongly influenced by patientdoctor communication variables. In case of childbirth mode of delivery is the factor of concern. In this study most of the pregnant mother $(90.3 \%)$ expressed initial negative reaction or remained indifferent to the decision of CS. The main reasons of such negative attitude were fear of death, dislike of caesarean operation and previous bad experience. No reason of such reaction was also found. This result is consistent with the result of other studies ${ }^{25-27}$ where significant number of parturient were aversed to CS initially and the main causes were also fear of death and dislike of caesarean delivery.

In this study out of 423 study population $355(83.9 \%)$ expressed their overall satisfaction with caesarean delivery. Other studies ${ }^{23,27}$ in different countries reported that $80 \%$ of the patients were satisfied with CS. Our study was done in a secondary level hospital which is the only referral hospital in the district. We talked to the parturient after $2^{\text {nd }}$ post- operative day during when their pain and discomfort were reduced and withstand their initial trauma. These maybe the contributing factor for slightly higher level of satisfaction.

The mean age of the patients was $23.99 \pm 5.29$ years and range was $18-45$ years. The satisfied women were slightly aged (mean age $24.3 \pm 5.3$ years) than unsatisfied women (mean age 22.1 \pm 4.5 years) and it was statistically significant. It was supported by other international studies ${ }^{27,28}$ where increasing maternal age was significantly associated with satisfaction for caesarean delivery. There was a significant association between the educational status of the patients and satisfaction with caesarean delivery. Educated patients are probably more careful about their own health and the health of their babies. They can understand physicians' language more easily at the counseling session about the indications of CS. The patients with elective CS had higher satisfaction than emergency operation. This probably due to in case of elective operation patients have got enough time for preparation and mind setup in favour of CS.

Table-IV reveals that all the 41 initial positive women became satisfied following caesarean delivery. Out of 304 initial negative women, 243(80.0\%) expressed their satisfaction with CS. A number of indifferent women (71 out of 78 ) also noticed their satisfaction following CS. It is obvious that both the initial positive and negative reaction to the decision of CS were statistically significantly associated with satisfaction following CS $(p<0.05)$. The significant association was also found in the study done by Enabudoso $\mathrm{E}$ and Isara $\mathrm{AR}^{27}$ in Nigeria.

This study was done on the $2^{\text {nd }}$ to $6^{\text {th }}$ post-operative day when the mothers were very emotional and happy with their babies. Getting a healthy baby mother may forget all the pains, distresses and negative feelings associated with CS. On the other hand patients of major complications were excluded from the study. These may be the possible explanation of disparity between initial negative reaction and number of satisfied mothers. Similar views have been reported in earlier studies ${ }^{29-31}$.

In conclusion, there was a high level of satisfaction in the mother who delivered by CS. Although this study did not explore the specific areas of satisfaction like satisfaction with hospital facilities, services provided by health care providers, it may be regarded as the preliminary survey for the future in-depth study. 


\section{References:}

1. Molina G, Weiser TG, Lipsitz SR, Esquivel MM, Uribe-Leitz T, Azad T, et al. Relationship between cesarean delivery rate and maternal and neonatal mortality. JAMA 2015; 314(21):2263-2270.

2. Bell JS, Campbell DM, Graham WJ, Penney GC, Ryan M, Hall MH. Do obstetric complications explain high caesarean section rates among women over 30 ? A retrospective analysis. BMJ 2001;322:894-895.

3. Mac Dorman MF, Menacker F, Declercq E. Cesarean birth in the United States: Epidemiology, trends, and outcomes. Clin Perinatol 2008; 35(2):293-307.

4. Litorp H, Kidanto HI, Nystrom L, Darj E, Essen B. Increasing caesarean section rates among low risk groups: a panel study classifying deliveries according to Robson at a university hospital in Tanzania. BMC Pregnancy Childbirth 2013; 13:107.

5. Khan A, Ghani T, Rahim A, Rahman MM. Changing Trends in incidence and indications of caesarean section. Mymensingh Med J 2014; 23(1):52-55.

6. Sjögren B, Thomassen P. Obstetric outcome in 100 women with severe anxiety over childbirth. Acta Obstet Gynecol Scand 1997; 76: 948-952.

7. Ryding EL, Wijma B, Wijma K, Rydhström $\mathrm{H}$. Fear of childbirth during pregnancy may increase the risk of emergency caesarean section. Acta Obstet Gynecoi Scand 1998; 77:542-547.

8. Handa VL, Harvey L, Fox He, Kjerulff KH. Parity and route of delivery: does cesarean delivery reduce bladder symptoms later in life? Am J Obstet Gynecol 2004; 191: 463-469.

9. Dietz HP, Wilson PD. Childbirth and pelvic floor trauma. Best Pract Res Clin Obstet Gynaecol 2005; 19(6):913-924.

10. Dietz HP. Pelvic floor trauma following vaginal delivery. Curr Opin Obstet Gynaecol 2006; 18(5):528-537.

11. Chigbu CO, Ezeome IV, Iloabachie GC. Cesarean section on request in a developing country. Int J Gynecol Obstet 2007; 96(1):54-56.
12. Martin JA, Hamilton BE, Sutton PD, Ventura SJ, Menacker F, Kirmeyer S, et al. Births: final data for 2005. Natl vital stat Rep 2007; 56(6): 1-103.

13. Kirin TF. Elective caesarean section may suppress onset of PPHN. Ob Gyn News 2000;35:13.

14. Madar J, Richmond S, Hey E. Hyaline membrane disease after elective delivery at “Term”. Acta Pediatr 1999;88:1244-1284.

15. Lyndo-Rochelle M, Holt VL, Martin DP, Easterling TR. Association between Maternal Delivery and Maternal rehospitalization. JAMA 2000; 283:2411-2416.

16. Hemminki E, Merilainen J. Long-term effects of caesarean section: Ectopic pregnancies and placental problems. Am J Obstet Gynecol 1996;174:1569-1574.

17. Kwawukuma EY. Caesarean section in Developing countries. Best pract Res Clin Obstet Gynaecol 2001;15:165-178.

18. Okunufua F. Optimising caesarean section rates in West Africa. Lancet 2001; 358:1289.

19. Padkil F, Harwood T. Patient satisfaction in a preoperative clinic : an analysis using SERVQUAL Dimensions. Tot Qual Manag 2005; 16(1): 15-30.

20. Oliver RL. Satisfaction"a behavioural perspective on the consumer. Irwin/McGrawHill, Boston MA 1997.

21. Hildingsson I, Radestad I, Rubertsson C, Waldenstrom U. Few women wish to be delivered by caesarean section. $\mathrm{Br} \mathrm{J}$ Obset Gynaecol 2002;109:618-623.

22. Hickson GB, Clayton EW, Githens PB, Sloan FA. Factors that prompted families to file medical malpractice claims following perinatal injuries. J Am Med Assoc 1992; 267(10): 13591363.

23. Siassakos D, Clark J, Sibanda T, Attilakos G, Jefferys $A$, Cullen $L$, et al. A simple tool to measure patient perceptions of operative birth. $\mathrm{Br} J$ Obstet Gynaecol 2009; 116(13): 17551761.

24. Jackson J, Chamberlin J, Kroenke K. Predictors of patient satisfaction. Soci Scien Med 2001; 52:609-620. 
25. Aziken M, Omo-Aghoja L, Okonofua F. Perceptions and attitudes of pregnant women towards caesarean section in urban Nigeria. Acta Obstet Gynecol Scand 2007;86(1):42-47.

26. Cligbu CO, Iloabachie GC. The burden of caesarean section refusal in a developing country setting. $\mathrm{Br} J$ Obstet Gynaecol 2007;114(10):1261-1265.

27. Enabudoso E, IsaraAR. Determinants of patient satisfaction after cesarean delivery at a university teaching hospital in Nigeria. Int J Gynecol Obstet 2011; 114:251-254.
28. Orji EO, Ogunniyi SO, Onwudiegwu U. Beliefs and perceptions of pregnant women at llesa about caesarean section. Trop J Obstet Gynaecol 2003; 20(2): 141-143.

29. Marut JS. The special needs of the caesarean mother. Am J Matern Child Nurs 1978; 3: 202-206.

30. Elkin M. Having a section is having a baby. Birth Fam J 1977;4:2.

31. Affonso DD, Stichler JF. Caesarean birth. Women's reactions. AM J Nurs 1980;80: 468-470. 